\title{
Ion Transport through C-butyl-pyrogallol[4]arene-loaded Poly(Vinyl Chloride) Membranes
}

\author{
Silvânia Marilene de Lima Koller ${ }^{1}$, Henrique Dias Correia ${ }^{2}$, Tiago Mateus Bezerra \\ Teodósio $^{3}$, Thiago de Souza Cavallini ${ }^{4}$ and Grégoire Jean-François Demets ${ }^{4, *}$ \\ ${ }^{1}$ Insituto Nacional de Propriedade Industrial, rua Mayrnk Veiga, 9 Rio de Janeiro, R.J. CEP: 20090-910, \\ Brazil \\ ${ }^{2}$ Etec Angelo Cavalheiro, Av. José Correia Filho, 750, Serrana, S.P. CEP: 14150-000, Brazil \\ ${ }^{3}$ E.E. Adalberto Nascimento, R. Adalberto Maia, 235, Campinas, SP. CEP: 13076-015, Brazil \\ ${ }^{4}$ Universidade de São Paulo, Faculdade de Filosofia, Ciências e Letras de Ribeirão Preto, Ribeirão Preto, \\ SP. CEP: 14040-901, Brazil
}

\begin{abstract}
The present paper studies the natural diffusion and migration of monovalent aqueous ions through pyrogallol[4]arene cavitand-loaded poly(vinyl chloride) solid-state membranes exposed to concentration gradients, and electric fields using electrodes coated with such membranes. We have observed that ion flux through these semipermeable membranes is directly proportional to the amount of macrocycle they contain. Ion size, in this particular case, is not the most important factor to limit ion flux, but solvation numbers and energies seem to play a much more important role in the whole process.
\end{abstract}

Keywords: Pyrogallol[4]arenes, semipermeable membranes, ionophore, electrochemistry, P.V.C.

\section{INTRODUCTION}

Research on membranes is an ever-growing field since membranes could solve several practical problems of our day-to-day life ranging from water management to energy storage. Reverse osmosis and nanofiltration membranes, for example, are essential to desalinize water, and high-performance semipermeable membranes are necessary for the development of high current densities batteries and fuel cells. These were only two examples of many that one could think about, but there are many other applications for this kind of membrane such as artificial skin, dialysis systems, gas purification and separation, clean rooms air filters, and many more [1-5]. Solid-state synthetic membranes (SSSM) occupy a big share of these markets, since they may be produced in many sizes with specific characteristics and properties. Among several ways and techniques to produce SSSMs, one is particularly interesting, which consists to insert hollow molecules, known as cavitands, in common polymeric matrices (poly(vinyl chloride) PVC, poly(urethane) PU, poly(vinylidene fluoride) PVDF, etc...). Cavitands are well known to form inclusion compounds, in which small guest species can enter and, in some cases, cross the cavities. When

*Address correspondence to this author at the Universidade de São Paulo, Faculdade de Filosofia, Ciências e Letras de Ribeirão Preto, Ribeirão Preto, SP. CEP: 14040-901, Brazil; Tel: 55163315 4860; Fax: 55163315 4838; E-mail: greg@usp.br dispersed in polymer masses, cavitands form aleatoryoriented hollow segments, through which small chemical species can hop and move across the polymer mass. This kind of membrane may be used for many specific applications among those we have mentioned above, like sensors, batteries, and ionselective electrodes [2,6-9]. Our group has produced several cavitand-loaded solid-state polymeric membranes this way, using resorcin[n]arenes, cucurbit[n]urils, bambus[n]urils, and hemicucurbit[n]urils to explore this property, and to test different cavitands regarding their selectivity and other characteristics $[10,11]$. Different cavitands will lead to different semipermeable membranes, due to differences between the nature of their cavity, and the affinity for the mobile species.

The condensation of aldehydes and pyrogallol or resorcinol in acid medium leads to cone-shaped macrocycles called pyrogallol[4]arenes and resorcin[4]arenas [12, 13]. These molecules are quite similar to calix[n]arenes and may be used as building blocks for large supramolecular structures, in particular molecular capsules, held together by several hydrogen bonds (Figure 1) [14-18].

These interesting supramolecular assemblies have been extensively investigated by several groups to understand their properties [19], their thermodynamic behavior [20], their stability, and their ability to 


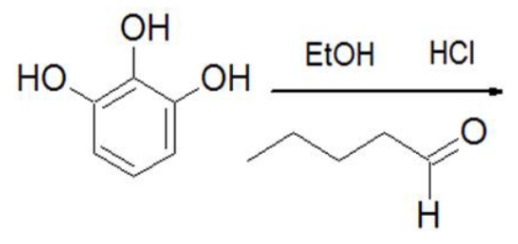

Figure 1: General structure of C-butyl pyrogallol[4]arene.

encapsulate/release several chemical species [21-23]. Pyrogallolarenes were also tested as artificial receptors for L-carnitine [24,25], for biochemical applications. Another interesting example was presented by Atwood and coworkers, when they prepared encapsulated drugs in C-butyl pyrogallol[4]arene by co-crystallization, and showed that such capsules are eligible for drug delivery purposes too [26].

In a previous paper, we have demonstrated that cucurbit[6]uril may act as an ion channel in polymers, and we were able to produce modified membraneelectrodes using ferrocene and a vanadium (IV) complex [27]. This time, we have employed pyrogallolarenes instead of cucurbiturils for their affinity for anions instead of cations, as is the case with cucurbiturils. We have prepared membranes made of poly(vinyl chloride) membranes containing several amounts of C-butyl pyrogallol[4]arene (C-Bpg4) to act as synthetic ion channels. We aim to verify if these molecules can transport cations across a solid poly(vinyl chloride) membrane, and how the nature and size of the ions could affect their transit.

\section{EXPERIMENTAL DETAILS}

\subsection{Chemicals}

C-butyl pyrogaloll[4]arene (C-Bpg4) was prepared and purified according to the procedure described by Mattay and coworkers [28] with minor adaptations. $5.10^{-3} \mathrm{~mol}$ of pyrogallol (Vetec) were dissolved in 30 $\mathrm{cm}^{3}$ ethanol (Synth). $5.10^{-3} \mathrm{~mol}$ of valeraldehyde (Synth) were added dropwise under nitrogen, and the mixture was kept under stirring for $15 \mathrm{~min}$., at $0{ }^{\circ} \mathrm{C}$. After this period, the temperature was raised to $80{ }^{\circ} \mathrm{C}$ for 6 hours. A precipitate was formed after the addition of $200 \mathrm{~cm}^{3}$ of water, it was filtered, washed with cold water, and dried for 2 hours at $80^{\circ} \mathrm{C}$ (red solid, yield 73 $\%$. ESI-MS methanol $\mathrm{m} / \mathrm{z}=775.8$ (pos) and 799.4 (neg)).

\subsection{Membranes}

Solid polymeric membranes were obtained dissolving $0.65 \mathrm{~g}$ of poly(vinyl chloride) resin (MB374;

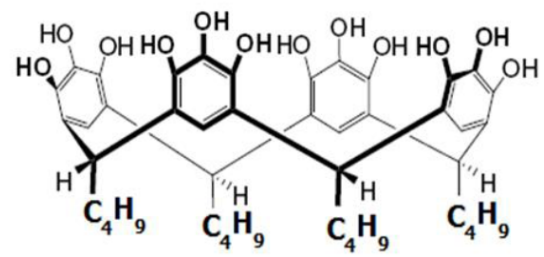

Solvay-Indupa do Brasil) in $30 \mathrm{~cm}^{3}$ tetrahydrofuran (Synth) altogether with varying amounts of C-Bpg4 $(10 \%, 20 \%$, or $43 \%$ in mass). These solutions were sprayed over a rotating glass disk (diam. $10 \mathrm{~cm}$.) and left drying for 20 minutes. After this period the films were peeled off from the substrate. The films were placed under vacuum for 24 hours before use, to eliminate all tetrahydrofuran residues. A control membrane was prepared without C-Bpg4. Membranes thickness was measured with an anvil precision micrometer (Zeiss Digital).

\subsection{Passive Diffusion Measurements}

Passive mass transport was measured to estimate the ability of several cationic species to cross the membranes pushed by simple concentration gradients in a universal diffusion cell (Figure 2) [29]. Ion concentrations were measured by conductimetry in the hypotonic compartment, using a Tecnopon mca 150 conductometer attached to a computer. Conductance data were converted in concentrations, using analytical curves, and instantaneous diffusion coefficients were calculated as follows: Hypotonic conductivity values were converted in concentrations ([Hypo]) using the angular coefficient of analytical curves obtained previously with the same equipment. Hypertonic concentrations were calculated subtracting [Hypo] from the nominal initial concentration, $[$ Hyper $]=[$ Initial $]-$ [Hypo], and the concentration gradient was calculated across both membrane interfaces, using its thickness $\delta ;\left(\nabla=\frac{[\text { Hyper }]-[\text { Hypo }]}{\delta}\right)$. Concentration gradients from the membrane interface and the conductimeter electrodes were assumed to be 0 since both compartments are kept under stirring, to homogenize the solutions. Instantaneous flux, $J_{\text {inst }}$, was calculated and normalized by the area $a$ of the membrane. In our apparatus (Figure 2) $\mathbf{a}=6.334 \times 10^{-4} \mathrm{~m}^{2}$ and $J_{\text {inst }}$ was calculated using concentration variation since the last measurement at a time $\left(\mathrm{t}_{-1}\right)$, using the expression: $J_{\text {inst }}=\frac{[\text { Hypo }]_{t}-[\text { Hypo }]_{t-1}}{\left(t-t_{-1}\right) \times a}$. Diffusion coefficients $D$ were calculated using an adaptation of Fick's law, $D=\frac{J_{\text {inst }}}{\nabla}$ and plotted against time. Measurements were realized at $25^{\circ} \mathrm{C}$. 


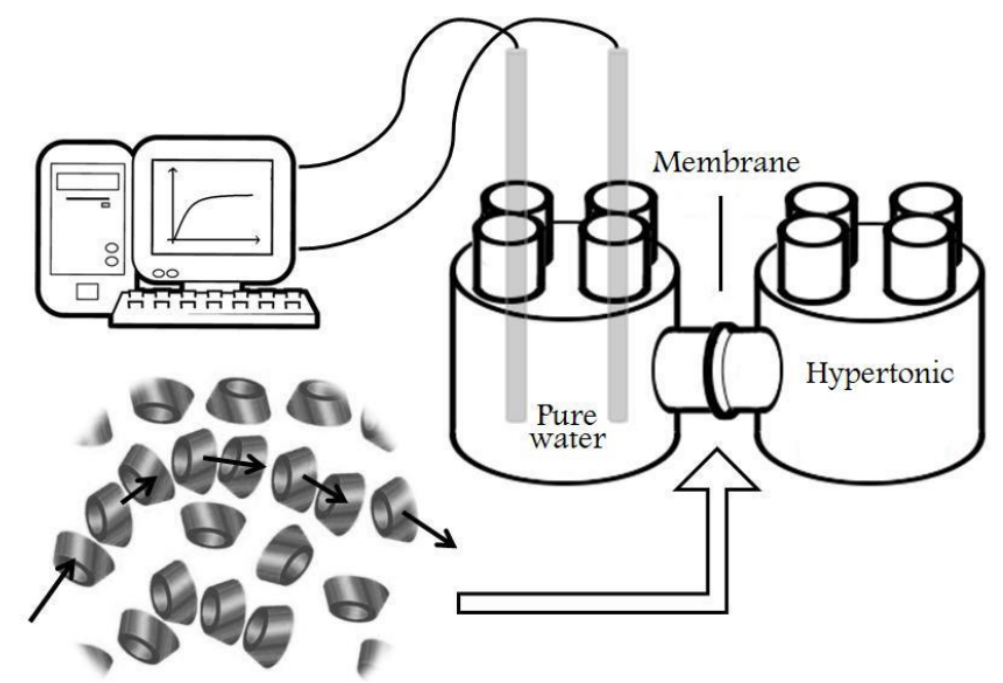

Figure 2: Experimental apparatus for natural diffusion measurements, with two sensors, one for temperature and another for conductivity. Inset: Illustration of the transit of an ion through several C-Bpg4 molecules.

\subsection{Chemically Modified Electrodes}

$2 \mathrm{mg}$ of ferrocene or vanadyl acetoacetate [VO (acac $)_{2}$ ] (Sigma-Aldrich ) were placed over fluorinedopped tin oxide electrodes (FTO; $1 \times 2.5 \mathrm{~cm}$ ), as described elsewhere [27]. The solids were covered with $20 \mu \mathrm{L}$ of a $10 \%$ C-Bpg4/PVC solution in tetrahydrofuran, the same as described above. The modified electrodes were dried at $50{ }^{\circ} \mathrm{C}$ for one hour to eliminate the solvent.

\subsection{Electrochemical Measurements}

All electrochemical measurements were carried out on a $\mu$ Autolab III potentiostat in a classical threeelectrode arrangement, using a platinum wire auxiliary electrode, an $\mathrm{Ag} / \mathrm{AgCl}$ reference electrode, and the modified FTO electrodes $(R=7 \Omega)$ as working electrodes. Aqueous $0.1 \mathrm{~mol} . \mathrm{dm}^{-3}$ solutions of $\mathrm{HNO}_{3}$, $\mathrm{HCl}, \mathrm{Cl}_{3} \mathrm{CCOOH}, \mathrm{NaCl}, \mathrm{NaNO}_{3}, \mathrm{KCl}$, and $\mathrm{KNO}_{3}$ were used as supporting electrolytes.

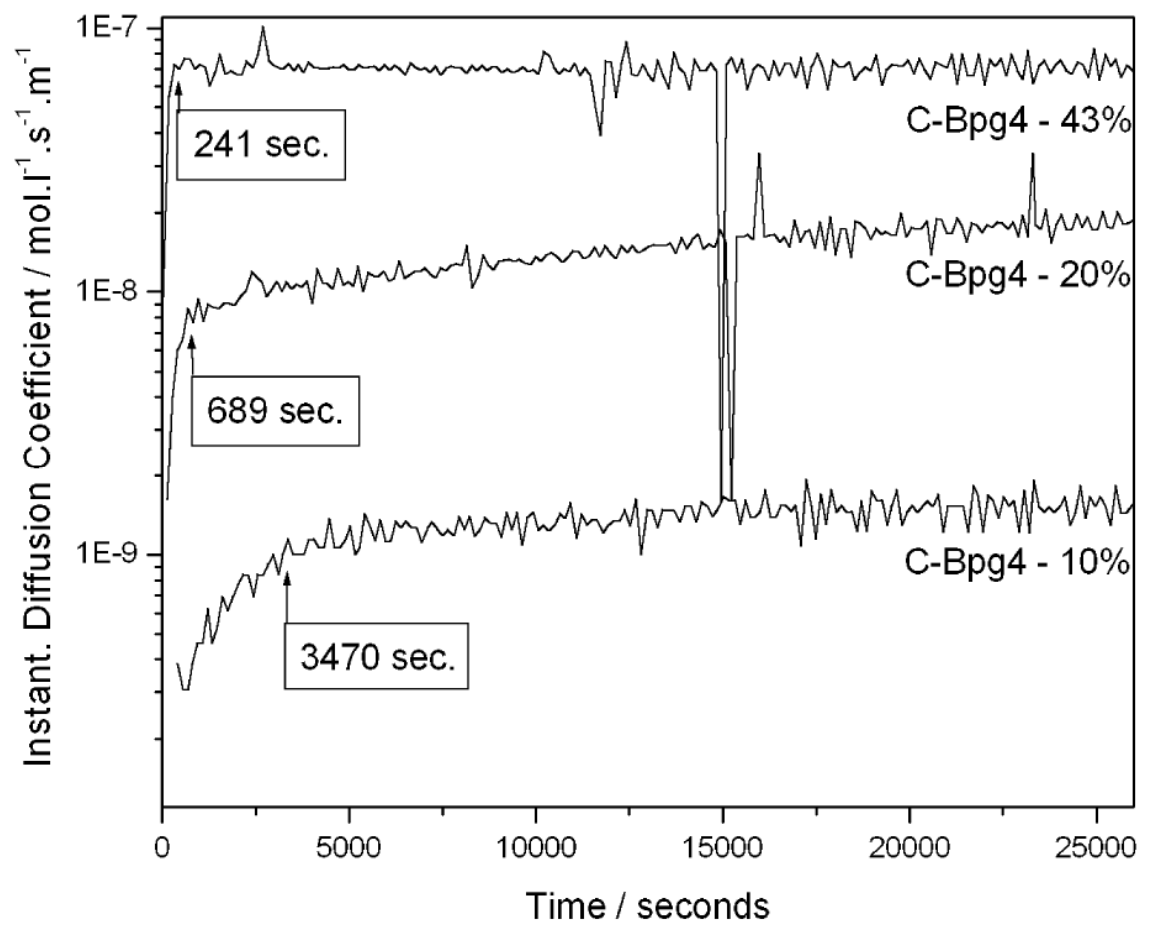

Figure 3: Instant diffusion coefficients as a function of time, for $\mathrm{HCl} 0.6 \mathrm{~mol}^{-\mathrm{dm}^{-3}}$ through 10,20 , and $43 \%, 100$ mm-thick CBpg4 PVC membranes. 


\section{RESULTS AND DISCUSSION}

\subsection{Natural Diffusion}

Our first goal was to prove that ions can permeate through C-Bpg4 cavities. To do so, 4 permeation experiments were carried out, using a pure PVC membrane, and three others containing respectively 10,20 , and $43 \%(\mathrm{~m} / \mathrm{m}) \mathrm{C}-\mathrm{Bpg} 4$, to separate pure water from $0.6 \mathrm{~mol} . \mathrm{dm}^{-3} \mathrm{HCl}$. No significant permeation could be measured by our apparatus for the pure PVC membrane so, the diffusion coefficient for this one was assumed as zero. The other 3 membranes were permeable to $\mathrm{HCl}$, and diffusion coefficients stabilized after swelling periods (Figure 3 ).

The swelling periods refer to the initial process of solvent permeation through the membranes. It is the period where diffusion coefficients are not constant. They range between 3470 seconds for the membrane containing $10 \% \mathrm{C}-\mathrm{Bpg} 4$, to 241 seconds for the one containing $43 \%$ of it. Diffusion coefficients increase with C-Bpg4 content too and data may be fitted by a polynomial regression of the second-order $\left(D=13.4^{-105}+[C-B p g 4]^{2} ; R^{2}=0.99\right)$. Swelling times follow the opposite behavior, being shorter for higher C-Bpg4 contents (Figure 4). These are strong evidence that permeation of ions and water depend on macrocycles' presence, occurring very probably by hopping between C-Bpg4 cavities instead of between the polymer's chains.
Cation size should affect its ability to move around and hop between adjacent C-Bpg4 molecules. The way ions travel through these polymers can also be influenced by solvation and desolvation processes associated with ions entering and leaving the cavities and interfaces of the membranes. For this reason, it is important to test several ions in the same conditions. Other experiments were realized using $\mathrm{LiCl}, \mathrm{NaCl}$, and $\mathrm{KCl} \quad 0.6 \mathrm{~mol} . \mathrm{dm}^{-3}$ instead of $\mathrm{HCl}$, and using membranes containing 20\% C-Bpg4 (Figure 5). To our surprise, the permeabilities of monovalent cations do not seem to depend on cation size exclusively, since $\mathrm{Na}^{+}$permeation is much smaller than other monovalent ions. $\mathrm{Na}^{+}$ion is not the biggest nor the smaller, hydrated or not, and should not be the slower of all the series. What would explain this is either a particularly high affinity between $\mathrm{Na}+$ and $\mathrm{C}-\mathrm{Bpg} 4$ or the fact that it is the anions and not the cations that limit the flux.

\subsection{Ion Migration}

Measuring ion-transport under electric fields, or migration, is a fast and effective way to study the effect of macrocycles inside the polymer matrix. Ferrocene is a very useful and well-behaved electrochemical scavenger in organic medium, it shows a reversible pair of peaks around $0.5 \mathrm{~V}$ vs saturated calomel electrode, and it is very reliable as an internal reference to study electrochemical processes. It is frequently used to study charge transport through chemically modified electrodes. We have used it this time as an

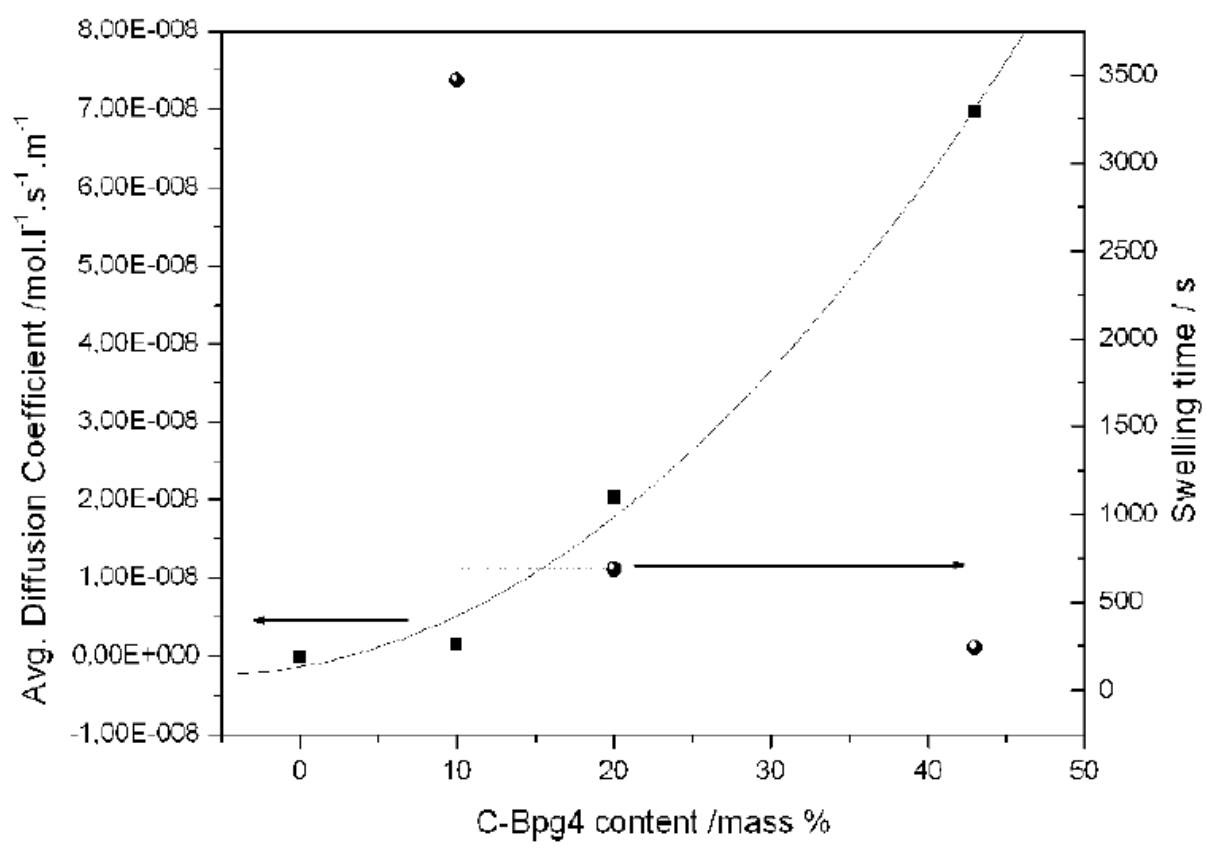

Figure 4: Average diffusion coefficients for $\mathrm{HCl} 0.6$ mol.dm-3 through 10, 20, and 43\% C-Bpg4 PVC membranes (squares) and swelling times of the same (balls). 


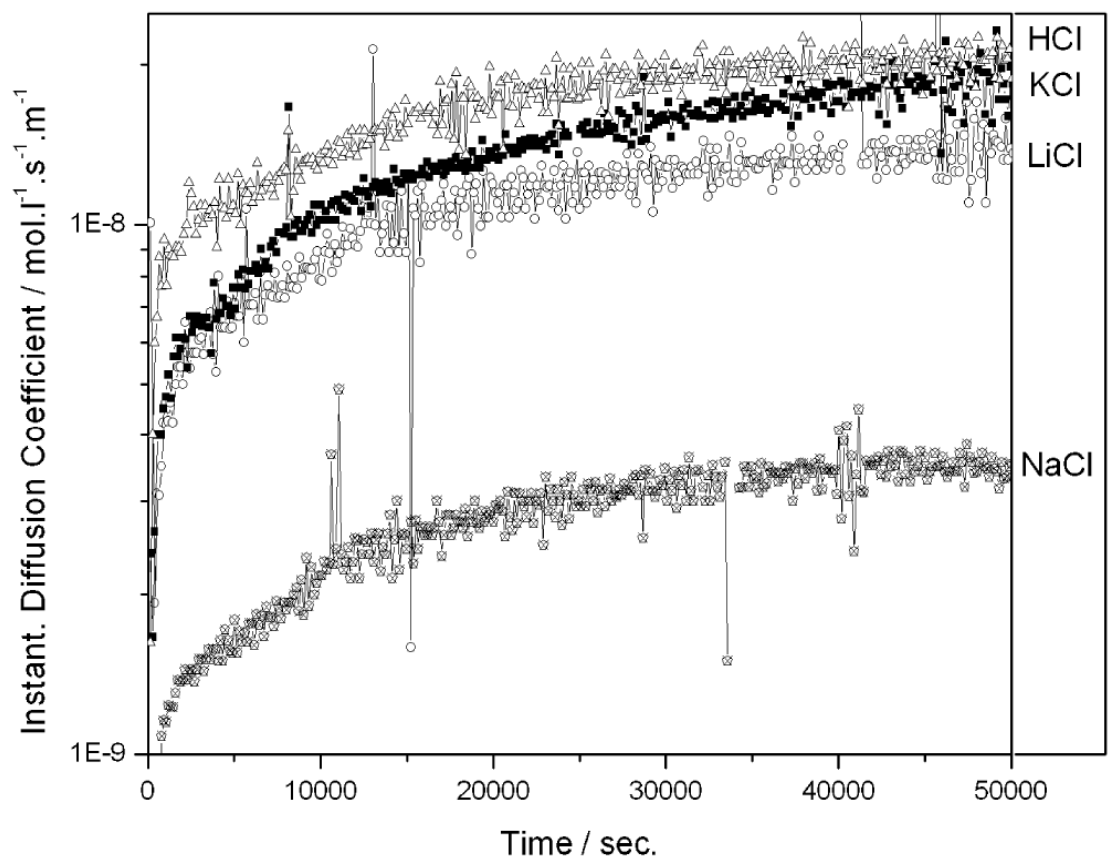

Figure 5: Instant diffusion coefficients as a function of time, for $\mathrm{HCl}$ (triangles), $\mathrm{KCl}$ (squares), $\mathrm{LiCl}$ (circles) and $\mathrm{NaCl}$ (pentagons) through a $120 \mu \mathrm{m}$ thick $20 \%$ C-Bpg4 PVC membrane. [Hypertonic] $=0.6 \mathrm{~mol}^{-\mathrm{dm}^{-3}}$.

internal scavenger, between the electrode and the polymeric membrane modifier. In this setup, faradaic processes would be compensated by charges coming from the electrolyte, as soon as they can cross the membrane that separates the scavenger from the solution. Immobilizing an electroactive species on an electrode and separating it from the electrolyte with such semipermeable membranes, is a good strategy to estimate electric field-driven diffusion, once it is the limiting step for charge compensation during redox processes taking place at the electrode's surface. It is a valuable tool to understand which species can migrate through the membranes. Difficult migration will generate overpotentials and irreversible electrochemical processes, and the typical signal of the scavenger will be misshapen. These electrodes were studied aqueous 0.1 mol. $\mathrm{dm}^{-3}$ acid solutions, with $\mathrm{HCl}$, $\mathrm{HNO}_{3}$, and $\mathrm{Cl}_{3} \mathrm{CCOOH}$ to estimate the influence of the anions by cyclic voltammetry. All three electrodes show symmetrical pair of waves around $0.15 \mathrm{~V}$ vs. $\mathrm{Ag} / \mathrm{AgCl}$, with different intensities according to the nature of the anions (Figure 6) The most intense current peaks correspond to $\mathrm{HNO}_{3}$, and the lesser to $\mathrm{HCl}$. Changing the electrolytes' anion (using single charged species, with different sizes e.g. $\mathrm{NO}_{3}{ }^{-}, \mathrm{Cl}^{-}$and $\mathrm{Cl}_{3} \mathrm{CCOO}^{-}$) peak current intensity decreases in this order: $\mathrm{i}_{p}\left(\mathrm{NO}_{3}{ }^{-}\right)$ $>\mathrm{i}_{\mathrm{p}}\left(\mathrm{Cl}_{3} \mathrm{CCOO}^{-}\right)>\mathrm{i}_{\mathrm{p}}\left(\mathrm{Cl}^{-}\right)$.

This behavior shows clearly too that the current is not totally dependent on the size of the anions too: larger ions should migrate less than the smaller, (see Table 1) and cannot compensate charge during ferrocenium ion formation.

Since it was quite clear that ionic radius is not the decisive factor to favor or notion flux, we decided to use similar ions in size, but different in structure, at

Table 1: Ionic Radii of the lons used in this Study

\begin{tabular}{|c|c|c|}
\hline Ion & Effective unhydrated Radius $(\mathbf{A})$ & Hydrated effective Radius $(\mathbf{A})$ \\
\hline \hline $\mathrm{Li}^{+}$ & 0.78 & 3.82 \\
\hline $\mathrm{Na}^{+}$ & 1.02 & 3.58 \\
\hline $\mathrm{K}^{+}$ & 1.33 & 3.31 \\
\hline $\mathrm{CCl}_{3} \mathrm{COO}^{-}$ & 2,67 & 3,5 \\
\hline $\mathrm{NO}_{3}^{-}$ & 2.64 & 3.35 \\
\hline $\mathrm{Cl}^{-}$ & 1.81 & 3.32 \\
\hline
\end{tabular}




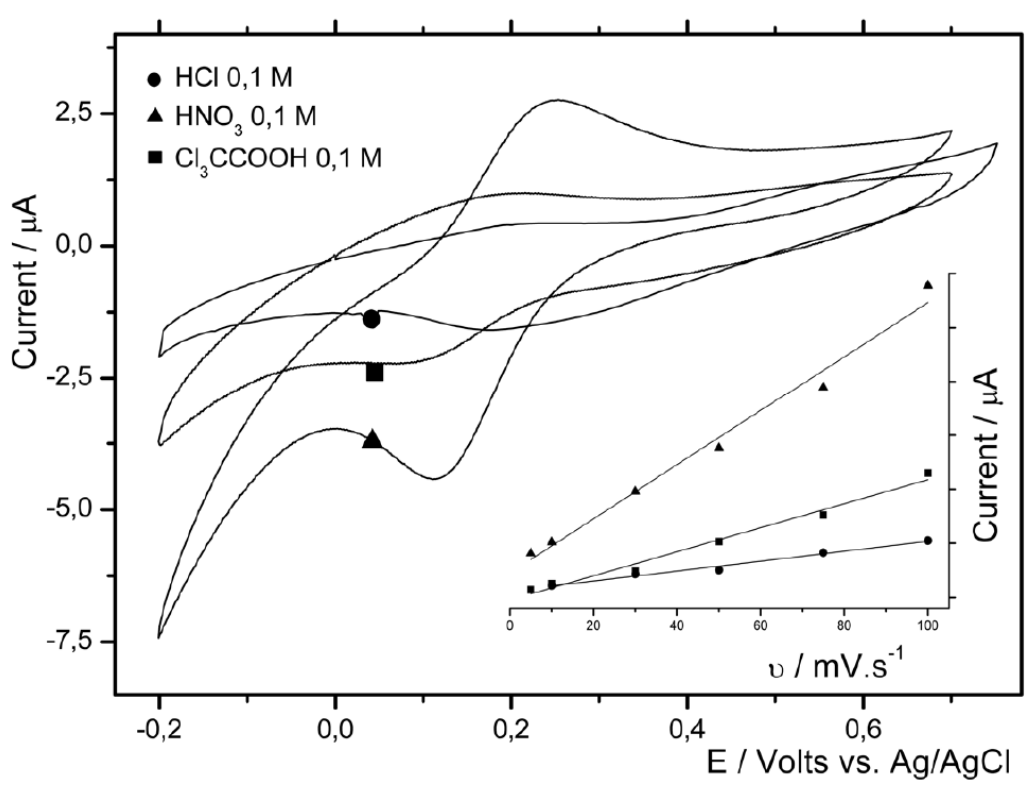

Figure 6: Cyclic voltammograms of ferrocene/PVC-Pg4 $10 \%$ modified electrodes in different aqueous acids at $10 \mathrm{mV}^{\mathrm{s}}{ }^{-1}$, in $\mathrm{HNO}_{3}, \mathrm{HCl}$, and $\mathrm{Cl}_{3} \mathrm{CCOOH}$ at 0.1 mol. $\mathrm{dm}^{-3}$. Inset: peak currents * vs. sweep rate.

least in the way they are solvated. Figure 7 shows the same experiment using exclusively small ions in pairs $\left(\mathrm{K}^{+}, \mathrm{Na}^{+}, \mathrm{Cl}^{-}\right.$, and $\left.\mathrm{NO}_{3}{ }^{-}\right)$. This time we could have a better idea of the limiting step for ion migration. The ferrocene/ferrocenium $(\mathrm{Fc} / \mathrm{Fc}+)$ process is visible for all ion pairs we have tested, but peaks for the reduction process (when cations should compensate charge) are more intense than oxidation ones (when anions are involved). Peaks for $\mathrm{Na}^{+}$salts are much smaller than for $\mathrm{K}^{+}$, indicating that this cation crosses the physical barrier faster than $\mathrm{Na}^{+}$. The anions play an important role too, once for each pair of cations, $\mathrm{NO}_{3}^{-}$anions were slightly better than $\mathrm{Cl}^{-}$.

According to these findings, it is reasonable to assume that solvation energies, solvation numbers, and frictional resistance are more important than ion size in this case. This is particularly relevant for these two cations in this concentration range, where there is a considerable difference between hydration numbers $\left(\mathrm{K}^{+}=3 ; \mathrm{Na}^{+}=4\right)$ and hydration free-energy $\left(\mathrm{K}^{+}=-295\right.$; $\left.\mathrm{Na}^{+}=-365 \mathrm{~kJ} \mathrm{~mol}^{-1}\right)$. This information suggests that ions

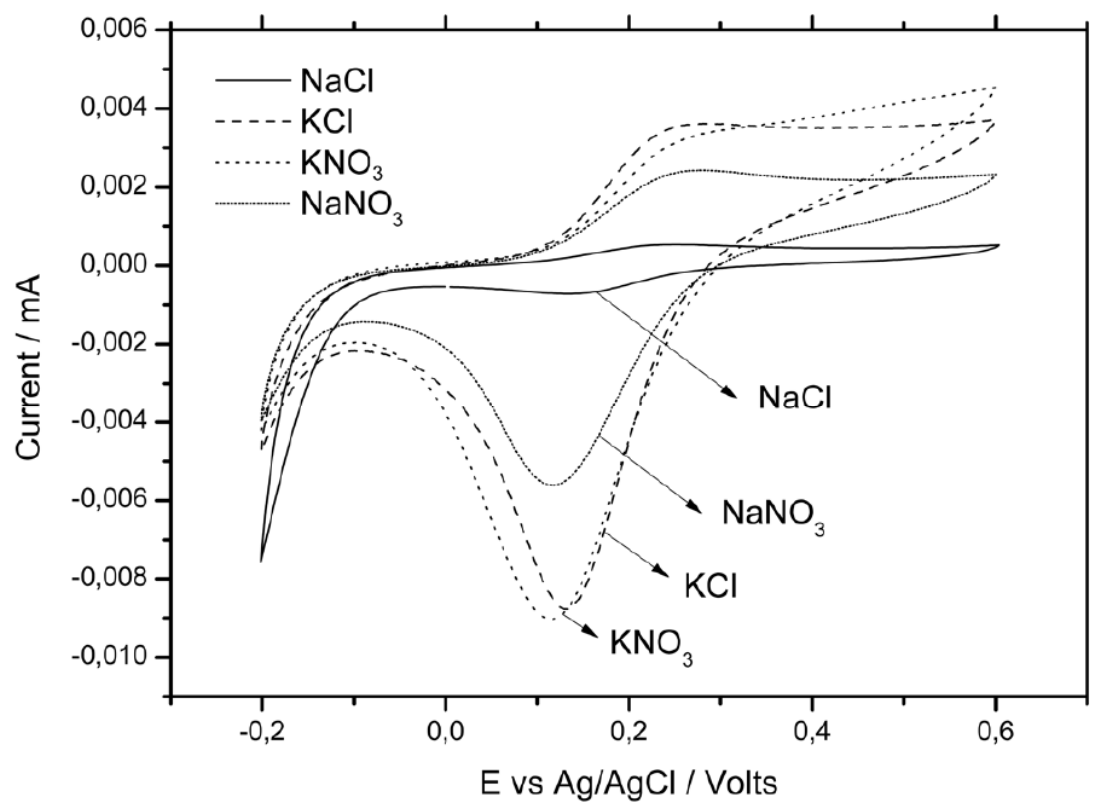

Figure 7: Cyclic Voltammograms of ferrocene in membrane modified electrodes, in different electrolytes, combining big and small anions and cations. 


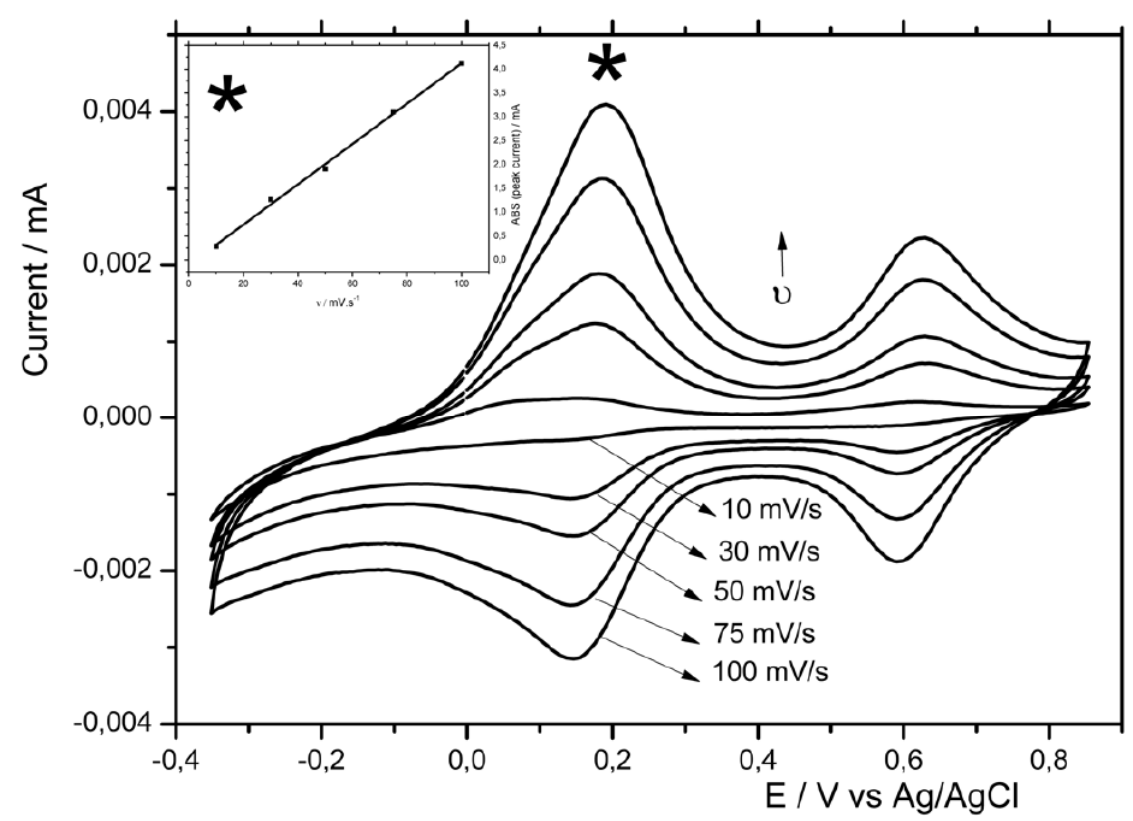

Figure 8: [VO(acac $)_{2}$ ] cyclic voltammograms at different sweep rates, in $\mathrm{HNO}_{3} 0.1$ mol.dm ${ }^{-3}$ under a $10 \% \mathrm{Pg} 4 / \mathrm{PVC}$ film. Inset: peak currents ${ }^{*}$ vs. sweep rate.

cross the membranes dehydrated, and the limiting step for ion crossing would be the dismantlement of their solvation sphere. This conclusion is very coherent, but it is not always the case with other cavitands as for cucurbit[n]urils for example, where ions flow hydrated. $\left[\mathrm{VO}(\mathrm{acac})_{2}\right]$, as ferrocene, is another well-known electrochemical scavenger since it undergoes reversible redox processes in organic solvents, and it is used for the same reason and in the same way as ferrocene. Figure 8 shows the voltammograms of [VO(acac) $)_{2}$ modified electrode (covered with a membrane) in $\mathrm{HNO}_{3} 0.1$ mol. $\mathrm{dm}^{-3}$ at several sweep rates. Two pairs of waves $\left(\mathrm{V}^{\prime \prime \prime} / \mathrm{V}^{\mathrm{IV}}\right.$ and $\left.\mathrm{V}^{\mathrm{IV}} / \mathrm{V}^{\mathrm{V}}\right)$ are visible, indicating that charge compensation processes are occurring fast enough through the membrane with the smaller cations of our test set.

All peak currents grow linearly with scan rate, indicating that the electroactive species is immobilized on the electrode's surface. In $0.1 \mathrm{~mol}^{-\mathrm{dm}^{-3}}$ $\mathrm{HNO}_{3}$, two pairs of reversible peaks are clearly visible $\left(\mathrm{E}_{1 / 2}^{1}=0.17 \mathrm{~V} ; \Delta \mathrm{E}_{\mathrm{p}}=44 \mathrm{mV}\right.$ - probably $\left[\mathrm{VO}(\mathrm{acac})_{2}\right] \leftrightarrow$ [VO(acac $\left.)_{2}\right]^{+}$; and $\mathrm{E}_{1 / 2}^{2}=0.6 \mathrm{~V} ; \Delta \mathrm{E}_{\mathrm{p}}=33 \mathrm{mV}$, ip $\mathrm{p}_{\mathrm{c} 1} \sim 2 \mathrm{x}$ $\mathrm{i} \mathrm{p}_{\mathrm{c} 2}$, and $\left.\mathrm{ip}_{\mathrm{c}} \propto \mathrm{U}\right)$. A third process, much less intense, also occurs simultaneously with the first one $\left(E^{3}{ }_{1 / 2}=\right.$ $\left.0.02 \mathrm{~V} ; \Delta \mathrm{E}_{\mathrm{p}}=38 \mathrm{mV}\right)$. Normally, $\left[\mathrm{VO}(\mathrm{acac})_{2}\right]$ electrochemistry in solution is very complicated since the complex undergoes ligand rearrangement, coordination number changes, and deoxygenation/reoxygenation reactions. Most of these processes are irreversible in non-aqueous systems and many transient species react with water during electrochemical oxidation/reduction of [VO(acac $\left.)_{2}\right]$, as was demonstrated by Kitamura and Riechel [30,31]. Our experiment demonstrated not only that ions can reversibly cross PVC/C-Bpg4 membranes, but that it is possible to observe electrochemical reactions that were not supposed to occur since the electroactive species is immobilized and out of reach of the solvent molecules, which would impair them.

\section{CONCLUSION}

We have shown in the present paper that macrocycles like pyrogallolarenes allow ion transport through PVC films. They act as passive ionophores providing a free pathway to ion flux that is directly dependent on the C-Bpg4 amount in the polymeric matrix. The higher the C-Bpg4 concentration, the higher is the average diffusion coefficient, and the faster the swelling process occurs. This is an indication that water is somehow involved in the transport process, at least at the solid/liquid interfaces, but its role is not completely understood. Changing the size of the cations or anions, changes diffusion and migration too, and these diffusion coefficients do not follow any radius order, even dehydrated, nor hydrated radii, showing us that ion size is not the main barrier for ion flux through the system. Using similar-sized ion pairs we could observe that solvation numbers and solvation energies, especially for cations, are more important than size for ion flux, suggesting that these have to get 
rid of solvent molecules to get across the polymeric barrier.

\section{ACKNOWLEDGEMENTS}

The authors acknowledge CNPq-process 147842/2010-7 for financial support, Dr. Ivana Aprecida Borin, for RS-232 logging software, and Dr. Fritz Huguenin for lending his impedance cell.

\section{REFERENCES}

[1] Kovalev IV, Mal'bakhova IA, Vorob'ev AM, Borisenko TA, Popov MP, Matvienko AA, Titkov AI, Nemudryi AP. Microtube Membranes for the Selective Synthesis of Oxygen and Hydrogen. Russ J Electrochem 2021; 10: 1019-27. https://doi.org/10.1134/S1023193521100074

[2] Huang T, Alyami MZ, Kashab, NM, Nunes SP. Engineering membranes with macrocycles for precise molecular separations. J Mater Chem A 2021; 9(34): 18102-28. https://doi.org/10.1039/D1TA02982G

[3] Kim JP, Choi E, Kang J, Choi SE, Choi Y, Kwon O, Kim DW. Ultrafast $\mathrm{H}_{2}$-selective nanoporous multilayer graphene membrane prepared by confined thermal annealing. Chem Commun 2021; 57(70): 8730-3. https://doi.org/10.1039/D1CC02946K

[4] Han S, Ibrahim MYS, Abolhasani M. Intensified recovery of switchable hydrophilicity solvents in flow. Chem Commun 2021; 57(86): 11310-3.

https://doi.org/10.1039/D1CC03819B

[5] Jiang S, Hagesteijn KFL, Ni J, Ladewig BP. A scientometric study of the research on ion exchange membranes. RSC Adv 2018; 8(42): 24036-48 https://doi.org/10.1039/C8RA04686G

[6] Nagels LJ, Bazylak G, Zielinska D, Designing potentiometric sensor materials for the determination of organic ionizable substances in HPLC. Electroanal 2003; 15 (5-6): 533-8. https://doi.org/10.1002/elan.200390065

[7] Lukyanenko NG, TItova NY, Karpmchlk S, Melnrk T, Sodiumselective electrodes based on PVC membranes containing bis[(3n2 + 1)-crown-n] ether derivatives. Anal Chim Acta 1992; 259: 145-58. https://doi.org/10.1016/0003-2670(92)85087-M

[8] Ryba O, Petránek J, Interference of permeable anions in 21 potassium-sensitive membrane electrodes based on valinomycin and dimethyldibenzo-30-crown-10. J Electroanal Chem 1976; 67: 321-33. https://doi.org/10.1016/S0022-0728(76)80048-4

[9] Crawley CD, Rechnitz CA, Electrochemical studies on ionselective polymer membrane electrodes. J Membr Sci 1985; 24: 201-19. https://doi.org/10.1016/S0376-7388(00)80147-7

[10] Teodosio MB, Cavallini TS, Demets GJF, Correia HD, inventors; University of São Paulo, assignee. Semipermeable materials for nanofiltration of macromolecules, water purification, glycerol, ethanol, emulsions, pigment ink, gases and liquids, comprises cucurbit uril or hemi-cucurbit uril and solid matrix. Brazilian Patent BR201002556-A2. 2010.

[11] de Lima SM, Demets GJF, inventors; University of São Paulo, assignee. Polymer-based semipermeable membrane containing dispersed pyrogallolarenes and resorcinarenes, and its production process. Brazilian Patent BR1020130131970. 2013.

[12] Högberg AGS, Two stereoisomeric macrocyclic resorcinolacetaldehyde condensation products. J Org Chem 1980; 45 (22): 4498-500.

\section{https://doi.org/10.1021/jo01310a046}

[13] Bruno B, Flaria D, Laura N, Fabiola S, Valbuena LZ, Giovanni Z, Caterina F, Maurizio S, Andrea T, Fabiana C, Jochen LMCM, Bis(diamido)-bridged basket resorcin[4]arenes as enantioselective receptors for amino acids and amines. Eur J Org Chem 2007; (36): 5995-6002. https://doi.org/10.1002/ejoc.200700829

[14] Evan-Salem T, Baruch I, Avram L, Cohen Y, Palmer LC, Rebek. Jr. J, Resorcinarenes are hexameric capsules in solution, Proc Nat Acad Sci 2006; 103: 12296-300. https://doi.org/10.1073/pnas.0604757103

[15] Atwood JL, Barbour LJ, Jerga A, Hydrogen-bonded molecular capsules are stable in polar media. Chem Commun 2001; 2376-7. https://doi.org/10.1039/b106250f

[16] Atwood JL, Barbour LJ, Jerga A, On the synthesis and structure of the very large spherical capsules derived from hexamers of pyrogallol[4]arenes. J Supramol Chem 2001; 1 (3): 131-4. https://doi.org/10.1016/S1472-7862(02)00003-5

[17] MacGillivray LR, Atwood JL, A chiral spherical molecular assembly held together by 60 hydrogen bonds. Nature 1997 389: 469-72.

https://doi.org/10.1038/38985

[18] Beyeh NK, Kogej M, Ahman A, Rissanen K, Schalley CA, Flying capsules: mass spectrometric detection of pyrogallolarene and resorcinarene hexamers, Angew Chem Int Ed Engl 2006; 45: 5214-8. https://doi.org/10.1002/anie.200600687

[19] Barrett ES, Dale TJ, Rebek Jr J, Stability, dynamics, and selectivity in the assembly of hydrogen-bonded hexameric capsules. J Am Chem Soc 2008; 130: 2344-50. https://doi.org/10.1021/ja078009p

[20] Yamanaka M, Shivanyuk A, Rebek Jr J, Kinetics and thermodynamics of hexameric capsule formation. J Am Chem Soc 2004; 126: 2939-43. https://doi.org/10.1021/ja037035u

[21] Schnatwinkel B, Rekharsky MV, Brodbeck R, Borovkov VV Inoue $\mathrm{Y}$, Mattay $\mathrm{J}$, Thermodynamic aspects of the host guest chemistry of pyrogallol[4]arenes and peralkylated ammonium cations. Tetrahedron 2009; 65 (13): 2711-5. https://doi.org/10.1016/j.tet.2009.01.066

[22] Shivanyuk A, Rebek Jr J, Reversible encapsulation by selfassembling resorcinarene subunits. Proc Natl Acad Sci U. S. A. $2001 ; 98$ : 7662-5. https://doi.org/10.1073/pnas.141226898

[23] Shivanyuk A, Rebek. Jr. J, Reversible encapsulation of multiple, neutral guests in hexameric resorcinarene hosts. Chemical Commun 2001; 2424-5. https://doi.org/10.1039/b109464p

[24] Schnatwinkel B, Rekharsky MV, Borovkov VV, Inoue $Y$, Mattay J, Pyrogallol[4]arenes as artificial receptors for Icarnitine. Tetrahedron Lett 2009; 50 (13): 1374-6. https://doi.org/10.1016/j.tetlet.2008.10.108

[25] Wirtheim E, Avram L, Cohen Y, Thio-ether-footed resorcin[4]arenes: self-assembly in solution and interaction with gold nanoparticles as viewed by diffusion NMR. Tetrahedron 2009; 65 (35): 7268-76. https://doi.org/10.1016/j.tet.2009.02.083

[26] Fowler DA, Tian J, Barnes C, Teat SJ, Atwood JL, Cocrystallization of c-butyl pyrogallol[4]arene and c-propan3-ol pyrogallol[4]arene with gabapentin. Crystal Struct. Commun 2011; 13 (5): 1446-9. https://doi.org/10.1039/COCE00661K

[27] Correia HD, Demets GJF, Cucurbit[6]uril/PVC-based semipermeable membranes as electrode modifiers for electrochemical investigation of insoluble substrates, Electrochem. Commun. 2009; 11: 1928-31. https://doi.org/10.1016/j.elecom.2009.08.018 
[28] Gerkensmeier T, Iwanek W, Agena C, Fröhlich R, Kotila S,Näther C, Mattay J, Self-assembly of 2,8,14,20tetraisobutyl-5, 11, 17, 23-tetrahydroxyresorc [4] arene. Eur J Org Chem 1999: 2257-62.

https://doi.org/10.1002/(SICl)1099-

0690(199909)1999:9<2257::AID-EJOC2257>3.0.CO;2-H

[29] Teodósio TMB, de S. Cavallini T, Jardim LV, Demets GJF, Montagem de uma célula universal para ensaios de permeação em membranas semipermeáveis sólidas em escala laboratorial. Orbital Elec J Chem Campo Grande 2011; 3: 204-11.
[30] Kitamura M, Yamashita K, Imai H, Studies on the Electrode Processes of Oxovanadium(IV). II. Electrolytic Reduction of Vanadyl Acetylacetonate in Acetonitrile Solution at Mercury Electrode. Bull Chem Soc Jpn 1976; 49(1): 97-100.

https://doi.org/10.1246/bcsj. 49.97

[31] Riechel TL, Sawyer DT. Electrochemical Studies of Vanadium(III),-(IV), and-(V) Complexes of 8-Quinolinol in Acetonitrile. Formation of a Binuclear Mixed-Valence (IV,V) Complex. Inorg Chem 1975; 14(8): 1869-75.

https://doi.org/10.1021/ic50150a028

Received on 30-10-2021

Accepted on 05-12-2021

Published on 10-12-2021

https://doi.org/10.6000/1929-5995.2021.10.11

(c) 2021 Koller et al.; Licensee Lifescience Global.

This is an open access article licensed under the terms of the Creative Commons Attribution License (http://creativecommons.org/licenses/by/4.0/) which permits unrestricted use, distribution and reproduction in any medium, provided the work is properly cited. 